\title{
Visual effects of colors on façades during rain
}

\author{
Takayuki Kumazawa ${ }^{1, *}$ \\ ${ }^{1}$ Assoc. Prof., Graduate School of Science and Engineering, Ibaraki University, 4-12-1 \\ Nakanarusawa, Hitachi, Japan
}

\begin{abstract}
In this study, rain would be regarded as an important factor in landscape color planning, and the visual effects and impressions of colors on façades during rainfall were focused. Verification experiments in which the authors produced a rain simulation device that can control rainfall and illuminance were conducted. Experiments were conducted based on an experimental design with four factors of hue $(5 \mathrm{R} / 5 \mathrm{Y} / 5 \mathrm{G} / 5 \mathrm{~PB})$, Chroma, lightness, and rainfall. In the rainfall simulation experiment, the visual effects of the color based on visual colorimetry were evaluated, and impression evaluations were extracted. As results, this study presented our findings about the relationship between rainfall and the visual effects and impressions of color, and determined that there are differences in the evaluation depending on the Hue and the amount of rainfall. In landscape color planning, considering the influence of rainfall is important for a fascinating landscape. This study will show basic important references of such new landscape color planning.
\end{abstract}

\section{Background}

There are many days when it will rain in Japan. Culture and custom on rain are deeply rooted in everyday daily life. Rain is an important factor in capturing the landscape, and in Japan, rainfall has long been a feature of landscape appreciation. Generally, depending on the strength of rain, the size and density of raindrops and the speed of falling greatly differ. As a result, landscape appearance will vary depending on the situation of rain. The appearance with the strength of rain is one of the important landscape features of rain. However, it is unknown how the appearance of the facade color changes in the rain. Besides, there are no studies about visual positive effects of colors on facades during rain. In Japan, as there is much rain season, landscape planning and landscape color plans should have been focusing on rainy landscapes.

In this study, rain should be taken into consideration as an important factor in landscape color planning, and the visual effects and impression of colors on facades during rainfall were investigated.

\footnotetext{
${ }^{*}$ Corresponding author: takayuki.kumazawa.1@vc.ibaraki.ac.jp
} 


\section{Method}

\subsection{First investigation}

Firstly, the actual situation survey was conducted outdoors around Ibaraki University Hitachi campus. A building consisting of a facade color on the south side was selected. In figure 1, Facade color of the building was shown. And then, in table 1, Hue, Value and Chroma by color difference meter was shown. These were surveyed by visual colorimetric evaluation during daylight (10 o'clock - 14 o'clock) and evening (17 o'clock - 19 o'clock) during fine weather and rain. In table 2 , results by visual colorimetry on sunny or rainfall in the noon were sugested. And in table 3, results by visual colorimetry on sunny or rainfall in the evening were shown. As results, the recognition for value of color was changed for medium value of color at the time of fine weather and at the time of rain, and the recognition for Chroma of the color was changed at high Chroma color at the time of rain. Therefore, it turned out that a tendency of the appearance of the facade color at the time of rain depends on lightness, value and Chroma of color.

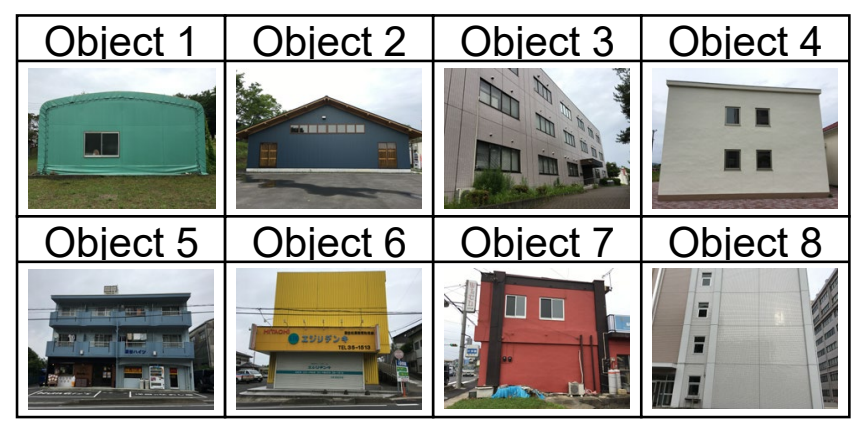

Fig.1. Facade colour of the building

Table 1. Hue, Value and Chroma by color difference meter

\begin{tabular}{l|l|l|l}
\hline Object & Hue & Value & Chroma \\
\hline Object 1 & $8.5 \mathrm{G}$ & 6 & 4 \\
Object 2 & $4.2 \mathrm{~B}$ & 3.9 & 1.3 \\
Object 3 & $1.8 \mathrm{Y}$ & 6.8 & 0.9 \\
Object 4 & $5.2 \mathrm{GY}$ & 8.9 & 1.5 \\
Object 5 & $8.3 \mathrm{BG}$ & 7.6 & 1.6 \\
Object 6 & $6.9 \mathrm{Y}$ & 7.4 & 9 \\
Object 7 & $8.0 \mathrm{R}$ & 4.2 & 5.2 \\
Object 8 & $8.5 \mathrm{GY}$ & 7.9 & 1
\end{tabular}


Table 2. Results by Visual colorimetry on sunny or rainfall in the noon

\begin{tabular}{|c|c|c|c|c|c|c|c|}
\hline \multirow[b]{2}{*}{ Value } & \multicolumn{2}{|c|}{ Sunny day (Noon) } & \multicolumn{2}{|c|}{ Rainfall day (Noon) } & \multirow[b]{2}{*}{$\mathrm{t}$} & \multirow[b]{2}{*}{$\mathrm{p}$} & \multirow[b]{2}{*}{ t-test } \\
\hline & $M$ & SD & $M$ & SD & & & \\
\hline Object 1 & 7.55 & 1.32 & 7.05 & 0.78 & -1.425 & 0.162 & - \\
\hline Object 2 & 3.70 & 0.86 & 3.89 & 1.10 & 0.616 & 0.541 & - \\
\hline Object 3 & 8.90 & 0.31 & 8.74 & 0.45 & -1.323 & 0.194 & - \\
\hline Object 4 & 9.00 & 0.00 & 9.00 & 0.00 & - & - & - \\
\hline Object 5 & 7.80 & 0.95 & 8.58 & 0.51 & 3.165 & 0.003 & $\star \star \star *$ \\
\hline Object 6 & 7.85 & 0.37 & 8.05 & 0.23 & 2.057 & 0.047 & ** \\
\hline Object 7 & 5.20 & 0.70 & 5.16 & 0.96 & -0.158 & 0.876 & - \\
\hline Object 8 & 8.95 & 0.22 & 8.89 & 0.32 & -0.634 & 0.530 & - \\
\hline Chroma & M & SD & $M$ & SD & $\mathrm{t}$ & $\mathrm{p}$ & t-test \\
\hline Object 1 & 4.30 & 1.81 & 5.00 & 1.25 & 1.399 & 0.170 & - \\
\hline Object 2 & 4.80 & 1.82 & 4.21 & 1.27 & -1.165 & 0.252 & - \\
\hline Object 3 & 1.90 & 0.55 & 1.58 & 0.84 & -1.420 & 0.164 & - \\
\hline Object 4 & 1.10 & 0.55 & 1.21 & 1.23 & 0.366 & 0.717 & - \\
\hline Object 5 & 2.85 & 2.03 & 2.05 & 0.62 & -1.637 & 0.110 & - \\
\hline Object 6 & 11.50 & 1.43 & 11.79 & 0.92 & 0.747 & 0.460 & - \\
\hline Object 7 & 8.95 & 2.24 & 8.79 & 3.28 & -0.180 & 0.858 & - \\
\hline $\begin{array}{l}\text { Object } 8 \\
{ }_{\star \star \star}, p<0.01\end{array}$ & 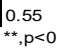 & 0.51 & 0.58 & 0.61 & 0.162 & 0.873 & - \\
\hline
\end{tabular}

Table 3. Results by Visual colorimetry on sunny or rainfall in the evening

\begin{tabular}{|c|c|c|c|c|c|c|c|}
\hline \multirow[b]{2}{*}{ Value } & \multicolumn{2}{|c|}{ Sunny day (Evening) } & \multicolumn{2}{|c|}{ Rainfall day (Evening) } & \multirow[b]{2}{*}{$t$} & \multirow[b]{2}{*}{$\mathrm{p}$} & \multirow[b]{2}{*}{ t-test } \\
\hline & $M$ & SD & $M$ & SD & & & \\
\hline Object 1 & 7.00 & 0.918 & 6.39 & 0.698 & -2.290 & 0.028 & ** \\
\hline Object 2 & 4.45 & 0.945 & 3.61 & 1.092 & -2.539 & 0.016 & ** \\
\hline Object 3 & 8.55 & 0.605 & 8.28 & 0.461 & -1.547 & 0.131 & - \\
\hline Object 4 & 9.00 & 0.000 & 8.94 & 0.236 & -1.056 & 0.298 & - \\
\hline Object 5 & 8.25 & 0.910 & 8.22 & 0.732 & -0.103 & 0.919 & - \\
\hline Object 6 & 8.10 & 0.308 & 8.17 & 0.383 & 0.594 & 0.556 & - \\
\hline Object 7 & 5.35 & 0.587 & 4.78 & 1.060 & -2.086 & 0.044 & ** \\
\hline Object 8 & 9.00 & 0.000 & 9.00 & 0.000 & - & - & - \\
\hline Chroma & $M$ & SD & $M$ & SD & $t$ & $\mathrm{p}$ & t-test \\
\hline Object 1 & 5.25 & 1.251 & 5.67 & 1.237 & 1.031 & 0.310 & - \\
\hline Object 2 & 4.30 & 1.689 & 5.39 & 1.720 & 1.967 & 0.057 & - \\
\hline Object 3 & 2.10 & 0.912 & 2.11 & 0.832 & 0.039 & 0.969 & - \\
\hline Object 4 & 1.45 & 0.686 & 1.22 & 0.428 & -1.211 & 0.234 & - \\
\hline Object 5 & 2.65 & 1.348 & 2.50 & 0.786 & -0.413 & 0.682 & - \\
\hline Object 6 & 9.40 & 2.836 & 12.78 & 1.215 & 4.677 & 0.000 & *** \\
\hline Object 7 & 9.70 & 2.080 & 10.33 & 1.414 & 1.085 & 0.285 & - \\
\hline 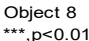 & 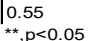 & 0.510 & 0.39 & 0.502 & -0.979 & 0.334 & - \\
\hline
\end{tabular}

\subsection{Second investigation}

Secondly, verification experiments were conducted in a rain simulation device that can control rainfall and illuminance. In figure 2 and 3, a plan of experiment device was shown. Experiments were conducted based on an experimental design with four factors of hue (5R / 5Y / 5G / 5PB), Chroma, lightness, and rainfall. In the rainfall simulation experiment, the visual effect of the color based on visual colorimetry, and conducted impression evaluations. In particular, the amount of rain and illuminance as conditions of the visual environment were changed. Subjects underwent the visual stimulus colorimetric evaluation of the stimulus. In figure 4, the levels of hue and Chroma in these experiments were shown. In table 4 , factors and levels of visual effects were shown. Factors of the visual effect were 
Hue, Chroma, Illuminance, and Rainfall. In the experiments, visual colorimetric evaluation using the Mansell color sheet at hand for the presented stimulus was conducted with varying rainfall. This evaluation experiments were also conducted at each illuminance. The experimental pattern is a total of 64 patterns of stimulus (hue: 4 levels / saturation: 2 levels) $\times$ rainfall (4 levels) $\times$ illuminance $(2$ levels $)$.

In addition, impression for participants was extracted by indicators for impression evaluation in table 5. After participants had an experience of experiment device, they answered their impression by using these indicators.
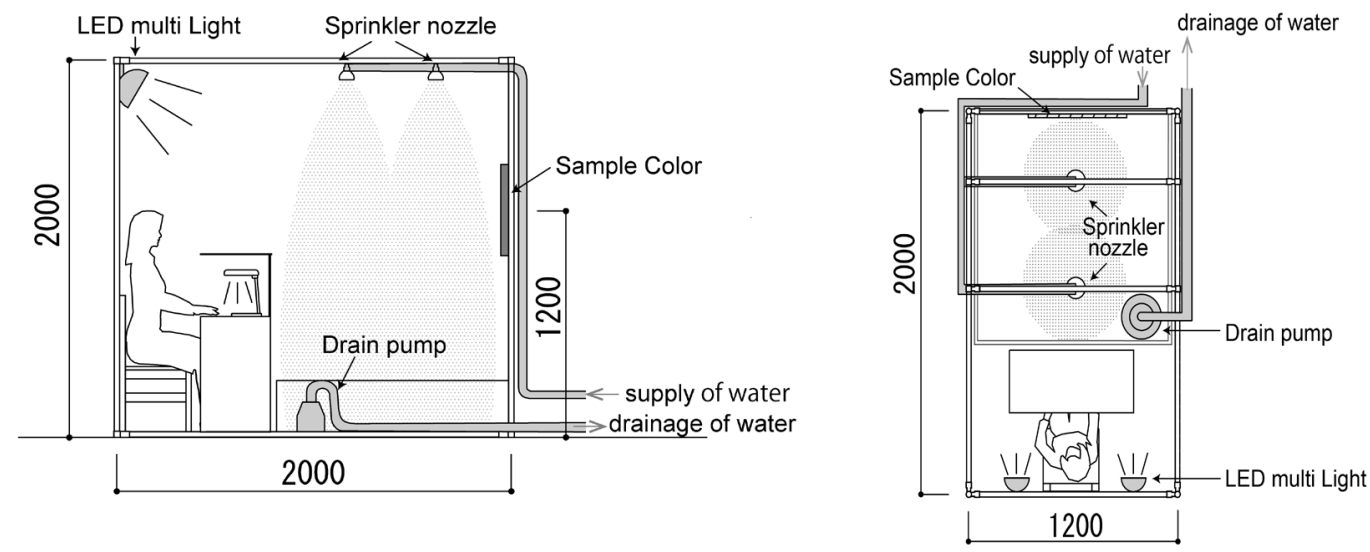

Fig.2. Laboratory sectional view

Fig.3. Plans of experiment device
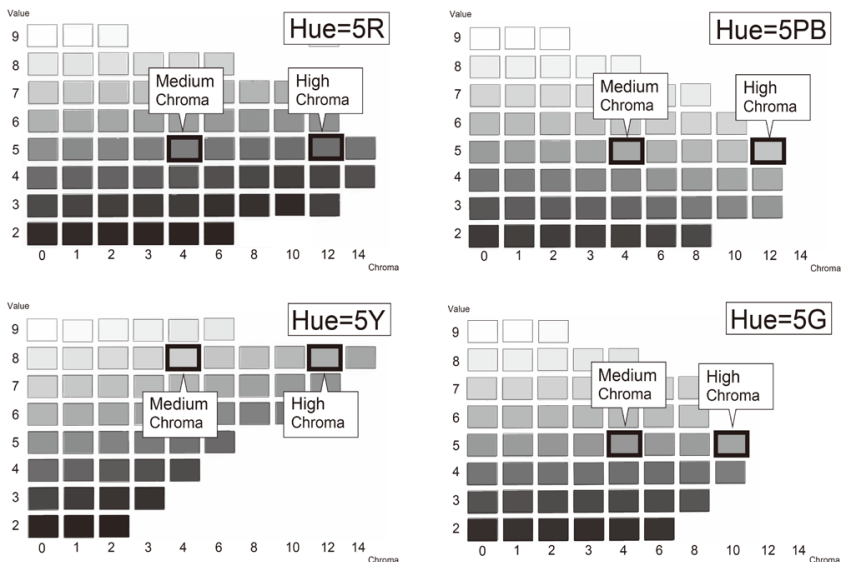

Fig.4. The levels of hue and Chroma in these experiments 
Table 4. Factors and levels of visual effects

\begin{tabular}{|c|c|c|c|c|c|c|}
\hline Factors & \multicolumn{4}{|c|}{ Level } & Pattern & Total \\
\hline Hue & $5 \mathrm{R}$ & $5 Y$ & $5 \mathrm{G}$ & $5 \mathrm{~PB}$ & 4 & \multirow{4}{*}{64} \\
\hline Chroma & \multicolumn{2}{|c|}{$\begin{array}{l}\text { Medium Chroma } \\
(\mathrm{C}=4)\end{array}$} & \multicolumn{2}{|c|}{$\begin{array}{c}\text { High Chroma } \\
(\mathrm{C}=10 \sim 12)\end{array}$} & 2 & \\
\hline Illuminance & \multicolumn{2}{|c|}{$\begin{array}{l}\text { Low illumination } \\
(1001 x)\end{array}$} & \multicolumn{2}{|c|}{$\begin{array}{l}\text { High illumination } \\
(1000 \mid x)\end{array}$} & 2 & \\
\hline $\begin{array}{c}\text { Amount of rainfall } \\
(\mathrm{mm} / \mathrm{h})\end{array}$ & $\begin{array}{l}\text { No rain } \\
0\end{array}$ & $\begin{array}{c}\text { Normal rain } \\
4\end{array}$ & $\begin{array}{l}\text { Slightly stronger rair } \\
11\end{array}$ & $\begin{array}{c}\text { Strong rain } \\
21\end{array}$ & 4 & \\
\hline
\end{tabular}

Table 5. Indicators for Impression Evaluation

\begin{tabular}{|c|c|c|c|c|c|c|c|c|}
\hline Evaluation & Evaluation scale $\rightarrow$ & 7 & 6 & 5 & 4 & 3 & 2 & 1 \\
\hline $\begin{array}{l}\text { 【Texture】 } \\
\text { 質感 }\end{array}$ & $\begin{array}{c}\text { Soft }- \text { Hard } \\
\text { やわらかいーかたい }\end{array}$ & $\begin{array}{c}\text { Very } \\
\text { soft } \\
\end{array}$ & Soft & $\begin{array}{c}\begin{array}{c}\text { Slightly } \\
\text { soft } \\
\mid\end{array} \\
\end{array}$ & $\begin{array}{l}\begin{array}{l}\text { No soft, } \\
\text { no hard }\end{array} \\
\end{array}$ & $\begin{array}{c}\begin{array}{c}\text { Slightly } \\
\text { hard }\end{array} \\
\end{array}$ & $\stackrel{\text { Hard }}{+}$ & $\begin{array}{l}\text { Very } \\
\text { hard }\end{array}$ \\
\hline $\begin{array}{c}\text { [Lively] } \\
\text { 生き生き感 }\end{array}$ & $\begin{array}{c}\text { Be lively - Be lifeless } \\
\text { 生き生きとした - 活気のない }\end{array}$ & $\begin{array}{c}\text { Very } \\
\text { be lively }\end{array}$ & Be lively & $\begin{array}{l}\begin{array}{c}\text { Slightly } \\
\text { be lively }\end{array} \\
\end{array}$ & $\begin{array}{l}\text { No be lively, } \\
\text { no be lifeless }\end{array}$ & $\begin{array}{c}\begin{array}{c}\text { Slightly } \\
\text { be lifeless } \\
\end{array} \\
\end{array}$ & Be lifeless & \begin{tabular}{|c|}
$\begin{array}{c}\text { Very } \\
\text { be lifeless }\end{array}$ \\
\end{tabular} \\
\hline $\begin{array}{l}\text { [Aesthetic】 } \\
\text { 美的感 }\end{array}$ & $\begin{array}{l}\text { Beautiful - Ugly } \\
\text { 美しい一醰い }\end{array}$ & $\begin{array}{c}\text { Very } \\
\text { beautiful } \\
\end{array}$ & Beautiful & 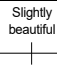 & $\begin{array}{c}\text { No beautiful, } \\
\text { no ugly }\end{array}$ & $\begin{array}{c}\text { Slightly } \\
\text { ugly } \\
\end{array}$ & $\stackrel{\text { Ugly }}{+}$ & $\begin{array}{l}\text { Very } \\
\text { ugly }\end{array}$ \\
\hline
\end{tabular}

\section{Results and discussion}

The data obtained by the subject's visual sense colorimetric evaluation was tabulated for each of Value and Chroma of the color. After aggregation, 4-way analysis of variance was carried out based on factors of hue, Chroma, illuminance and rainfall to show the effect on color. As results, many interactions were detected in hue. For this reason, analysis of variance was performed separately for each stimulus hue (5R / 5Y / 5G / 5PB). That is, a three-way configuration analysis of variance based on three factors of Chroma of color, illuminance and rainfall was carried out. In addition, it was judged that there was a significant difference when the significance level was 0.05 or less.

After verification experiments, the findings obtained by the verification are as follows. In Table 6, Visual effects on Value $(\mathrm{Hue}=5 \mathrm{R} / 5 \mathrm{Y} / 5 \mathrm{G} / 5 \mathrm{~PB})$ were shown. First, in order to examine the color lightness of the visual effect, visual colorimetry by Value of the color was conducted. It was found that the Value of the color got higher during rainfall. The color Hue $(5 \mathrm{R} / 5 \mathrm{G} / 5 \mathrm{~PB})$ showed that the lightness effect of the color Value was at its maximum in rainfall $11 \mathrm{~mm} / \mathrm{h}$, and above that the lightness effect of the color Value began decreasing. At the same time, the color of Hue $5 \mathrm{Y}$ showed that the lightness effect of the color Value increased as rainfall increased.

In table 7, visual effects on Chroma were shown. In order to examine the color saturation of the visual effect, we conducted visual colorimetry by Chroma of the color. Then, in figure 5, transitions of Chroma by rainfall difference (Hue $=5 \mathrm{R} / 5 \mathrm{Y} / 5 \mathrm{G} / 5 \mathrm{~PB})$ were shown. It was found that the Chroma of the color got lower at rainfall. The color of Hue $(5 \mathrm{Y} / 5 \mathrm{G} / 5 \mathrm{~PB})$ showed that the somber effect of the color Chroma increased with increasing rainfall. Other hand, the color of Hue $5 \mathrm{R}$ showed that the somber effect of the color Chroma decreased with increasing rainfall.

Also, in order to examine the texture as an impression of color, we evaluated impression. It was found that the color impression became soft during rainfall. It is thought that the lightness of the color increased because of the rainfall, hence softening the texture of the color. Impression was evaluated in order to examine liveliness as an impression of color. By analysis only the color of Hue $5 \mathrm{R}$ took on a lively impression at rainfall, with the 
effect reaching its maximum when rainfall was at $11 \mathrm{~mm} / \mathrm{h}$. It is thought that the movement of rain changed because of the rainfall, and the color took on a lively impression through its influence. Finally, impression was evaluated to examine the aesthetic sense of colors. It was demonstrated that only the warm color of Hue $(5 \mathrm{R} / 5 \mathrm{Y})$ took on a beautiful impression at rainfall. We believe that the movement of rain was changed by the rainfall, and the color took on a beautiful impression by its influence.

Table 6-1 Visual effects on【Value】(Hue $=5 \mathrm{R})$

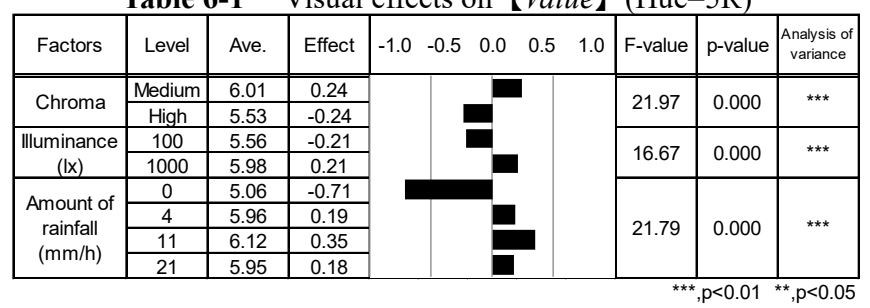

Table 6-2 Visual effects on【Value】 $(\mathrm{Hue}=5 \mathrm{Y})$

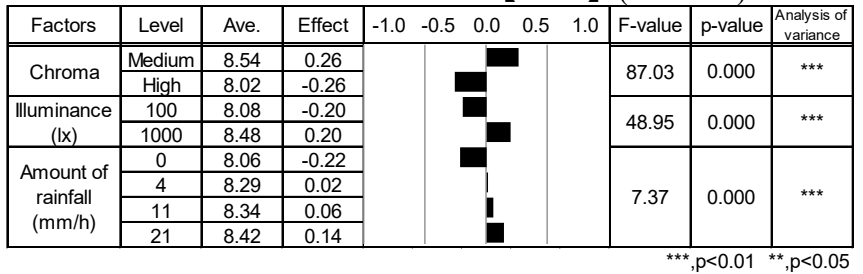

Table 6-3 Visual effects on【Value】(Hue $=5 \mathrm{G})$

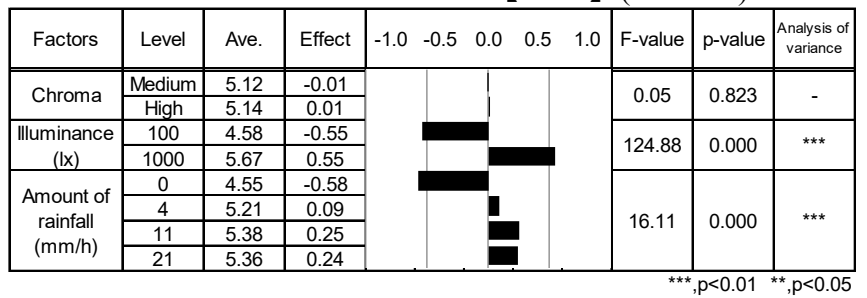

Table 6-4 Visual effects on【Value】 $(\mathrm{Hue}=5 \mathrm{~PB})$

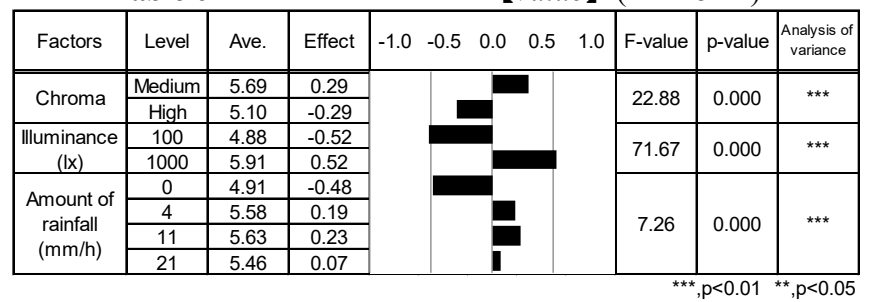


Table 7-1 Visual effects on 【Chroma】 (Hue=5R)

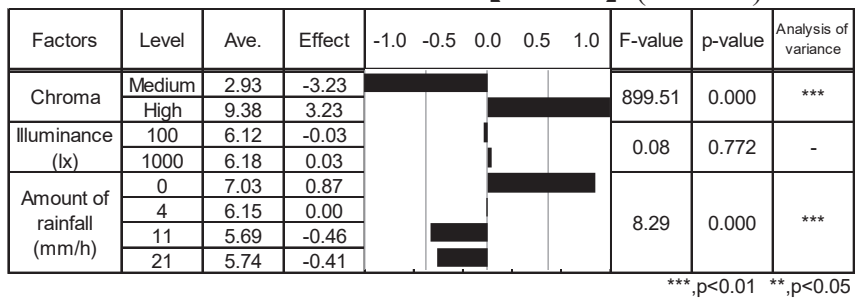

Table 7-2 Visual effects on 【Chroma】 (Hue $=5 \mathrm{Y})$

\begin{tabular}{|c|c|c|c|c|c|c|c|c|c|}
\hline Factors & Level & Ave. & Effect & $\begin{array}{lll}-1.0 & -0.5 & 0.0\end{array}$ & 0.5 & 1.0 & F-value & $\mathrm{p}$-value & \begin{tabular}{|c|} 
Analysis of \\
variance
\end{tabular} \\
\hline \multirow[b]{2}{*}{ Chroma } & Medium & 2.96 & -3.49 & & & & \multirow[b]{2}{*}{1237.12} & \multirow[b]{2}{*}{0.000} & \multirow{2}{*}{ *** } \\
\hline & High & 9.93 & 3.49 & & & & & & \\
\hline \multirow{2}{*}{$\begin{array}{c}\text { Illuminance } \\
(\mathrm{Ix})\end{array}$} & 100 & 6.41 & -0.04 & & & & \multirow{2}{*}{0.16} & \multirow{2}{*}{0.694} & \multirow[b]{2}{*}{ - } \\
\hline & 1000 & 6.48 & 0.04 & & & & & & \\
\hline \multirow{4}{*}{$\begin{array}{l}\text { Amount of } \\
\text { rainfall } \\
(\mathrm{mm} / \mathrm{h})\end{array}$} & 0 & 8.01 & 1.56 & & & & \multirow{4}{*}{30.72} & \multirow{4}{*}{0.000} & \multirow{4}{*}{$* * *$} \\
\hline & 4 & 6.43 & -0.02 & & & & & & \\
\hline & 11 & 5.72 & -0.73 & & & & & & \\
\hline & 21 & 5.63 & -0.81 & & & & & & \\
\hline
\end{tabular}

Table 7-3 Visual effects on 【Chroma】 (Hue $=5 \mathrm{G})$

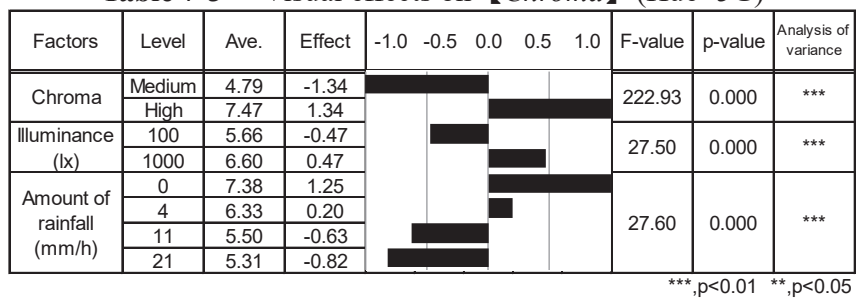

Table 7-4 Visual effects on 【Chroma】(Hue=5PB)

\begin{tabular}{|c|c|c|c|c|c|c|c|c|}
\hline Factors & Level & Ave. & Effect & $\begin{array}{lll}-1.0 & -0.5 & 0\end{array}$ & $0.5 \quad 1.0$ & F-value & $\mathrm{p}$-value & $\begin{array}{c}\text { Analysis of } \\
\text { variance }\end{array} \mid$ \\
\hline \multirow{2}{*}{ Chroma } & Medium & 3.57 & -2.51 & & & \multirow{2}{*}{697.56} & \multirow{2}{*}{0.000} & \multirow{2}{*}{$* * *$} \\
\hline & High & 8.60 & 2.51 & & & & & \\
\hline \multirow{2}{*}{$\begin{array}{c}\text { Illuminance } \\
\text { (Ix) }\end{array}$} & 100 & 5.56 & -0.52 & & & \multirow{2}{*}{30.46} & \multirow{2}{*}{0.000} & \multirow{2}{*}{$* * *$} \\
\hline & 1000 & 6.61 & 0.53 & & & & & \\
\hline \multirow{4}{*}{$\begin{array}{l}\text { Amount of } \\
\text { rainfall } \\
(\mathrm{mm} / \mathrm{h})\end{array}$} & 0 & 7.31 & 1.23 & & & \multirow{4}{*}{22.15} & \multirow{4}{*}{0.000} & \multirow{4}{*}{$* * *$} \\
\hline & 4 & 6.16 & 0.08 & & & & & \\
\hline & 11 & 5.57 & -0.52 & & & & & \\
\hline & 21 & 5.29 & -0.79 & & & & & \\
\hline
\end{tabular}

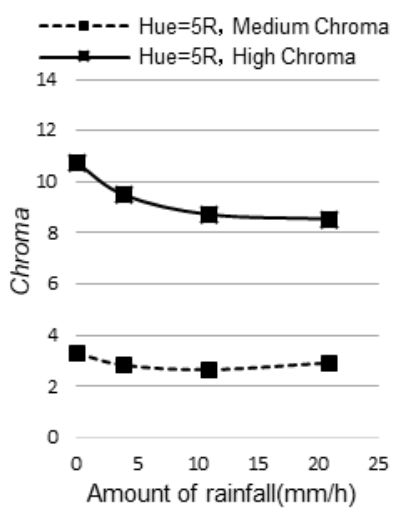

Fig.5-1【Chroma】 by rainfall difference(Hue $=5 \mathrm{R})$

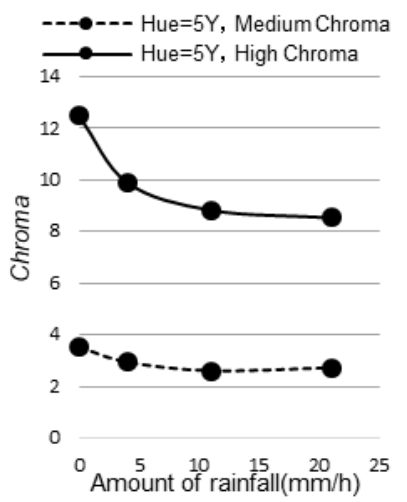

Fig.5-2【Chroma】 by rainfall difference $($ Hue $=5 \mathrm{Y})$ 


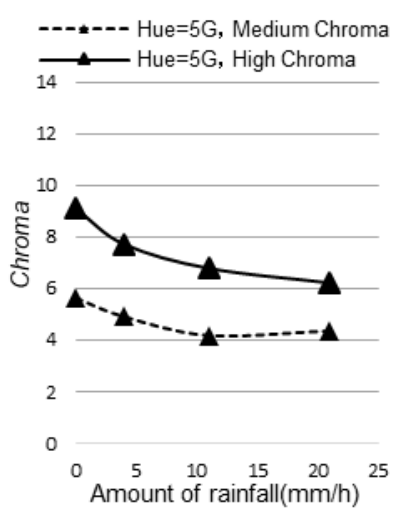

Fig.5-3【Chroma】by rainfall difference $($ Hue $=5 \mathrm{G})$

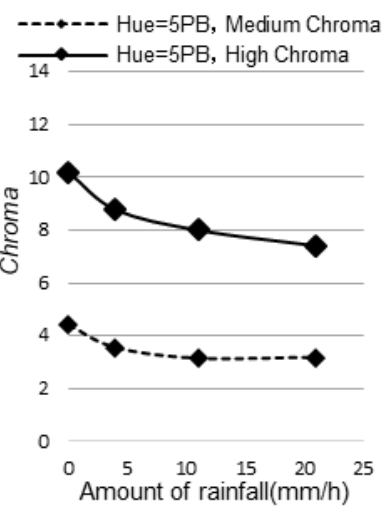

Fig.5-4【Chroma】by rainfall difference $($ Hue $=5 \mathrm{~PB})$

\section{Conclusion}

In this study, the relationship between rainfalls and the visual effects and impressions of color were confirmed, and there were differences in the evaluation depending on the Hue and the amount of rainfall. In landscape color planning, it was to consider the influence of rainfall is important for a fascinating landscape. This study will show basic important references of new landscape color plan.

This study was summarized as results of graduation research by Mika Kawakatsu who was a fourth grade student at the Ibaraki University. The author thanks his student for his work on this research.

\section{References}

1. Kobayashi, T. : A Study on the Effects of the Changing Scenery, journal of the Japanese Institute of Landscape Architecture (5), pp.279-282, 1987.3

2. Fukushima, H. and Horikoshi, T. : Realization of Climatic Landscape by fluctuation with weather and time for appearance of architecture, Summaries of Technical Papers of Annual Meeting, Architectural Institute of Japan, Urban Planning, pp.529-530, 2014.9

3. Takamatsu, $\mathrm{M}$ and Nakashima, $\mathrm{Y}$ and Yoshiwara, S. : Apparent Color of 10 Standard-color-cards in Dense Fog, Journal of the Color Science Association of Japan, pp.207-214, 1999.12

4. Kuwabara, Y and Takamatsu, $\mathrm{M}$ and Nakashima, $\mathrm{Y}$ and Terakawa, H and Tada, $\mathrm{K}$ and Iwane, H. : Visual Characteristics of Colored LED Lights In Dense Fog, Journal of the Color Science Association of Japan, pp. 86-87, 2012.5

5. Kawakatsu, $\mathrm{M}$ and Kumazawa, $\mathrm{T}$ : A study on changes in color appearance on facade during rain, Architectual Institute of Japan, pp739-740, 2017.7

6. Inoue, M and Kobayashi, T. : The Research Domain and Scale Construction of Adjective-Pairs In A Semantic Differential Method In Japan, The Japanese Association of Educational Psychology, pp. 253-260, 1985 